\title{
Preoperative Computed Tomographic Evaluation of Inferior Nasal Concha Hypertrophy and its Role in Deciding Surgical Treatment Modality in Patients with Deviated Nasal Septum
}

\author{
Evaluación Preoperatoria con Tomografía Computada de la Hipertrofia \\ de la Concha Nasal Inferior y su Rol en la Decisión de la Modalidad \\ de Tratamiento Quirúrgico en Pacientes con Tabique Nasal Desviado
}

Sumit Mrig; A. K. Agarwal \& J. C. Passey

MRIG, S.; AGARWAL; A. K. \& PASSEY, J. C. Preoperative computed tomographic evaluation of inferior turbinate hypertrophy and its role in deciding surgical treatment modality in patients with deviated nasal septum. Int. J. Morphol., 27(2):503-506, 2009.

SUMMARY: Deviated nasal septum is associated with compensatory hypertrophy of the inferior nasal concha on the contralateral side. In the past conventional septoplasty was done for the deviated septum, which would improve the patency on the side of deviation but would worsen it on the opposite side due to reallocation of the septum to the midline. The present study of 50 patients unfolds the anatomical composition of the inferior nasal concha based on the computed tomographic scan and help the otolaryngologist to determine whether to add turbinoplasty to standard septoplasty procedure or not.

KEY WORDS: Deviated nasal septum; Inferior nasal concha; Contralateral hypertrophy.

\section{INTRODUCTION}

In patients with nasal obstruction and anterior septal deviation to one side, a common finding is a varying degree of concomitant or compensatory inferior nasal concha hypertrophy in the side of the nose opposite the major septal deviation. A detailed description of the nasal conchas bones was first given by Casserius (1609) who recognized that three are usually present and consist of true bone, not cartilage (Pratt, 1915; Dixon, 1949) have described the common association of deviated nasal septum and contralateral inferior nasal concha enlargement.

The nasal conchas exists as three and sometimes four bilateral extensions form the lateral wall of the nasal cavity. At inspiration up to two-thirds of upper airway resistance is produced by the anterior tip of the inferior nasal concha in the region of the internal nasal valve. In a recent study on the nasal valve Haight \& Cole (1983) confirmed that "the greater portion of the nasal resistance is situated at the level of the anterior end of the inferior nasal concha".

Of the three nasal conchas the inferior nasal concha is the most susceptible to enlargement. It is seen that the inferior nasal concha hypertrophy is usually observed in septal deviation (Compensatory hypertrophy) and in allergic or vasomotor rhinitis (Lai \& Corey, 1983; Li et al., 1998).

Epidemiological investigations have shown that up to $20 \%$ of the population had chronic nasal obstruction caused by inferior nasal concha hypertrophy (Seeger et al., 2003).

Enlargement of the erectile mucosa of the inferior nasal concha significantly increases nasal airway resistance, contributing greatly to symptoms of nasal airway obstruction.

The common belief ascribes most of the enlargement of the inferior nasal concha to mucosal elements. Fairbanks (1984) claimed that it involves the bone as well as the mucosa and disclosed that the inferior nasal concha becomes thicker and spongier and arches further medially into the airway. It is important to note that the inferior nasal concha bone is thicker anteriorly than posteriorly (Proetz, 1944).

A histological study by (Berger et al., 2000) showed that the most commonly enlarged component of the contralateral inferior nasal concha in septal deviation is the bony nasal concha. 
The authors argued that these changes are not spontaneously reversible and should be corrected in conjunction with nasal septal surgery, which may relieve the obstruction on one side of the nose but leave the other side of the nose obstructed, because of reallocation of the septum toward the hypertrophic inferior nasal concha. Other authors have also recommended that concomitant surgery on the compensatory hypertrophic inferior nasal concha during septoplasty is advisable. To the best of our knowledge, the present study is first to uncover the dimensions and composition of the hypertrophic and the control inferior nasal concha by computed tomography (CT) scan. Such novel data can help the otolaryngologist to determine whether to add turbinoplasty to standard septoplasty procedure.

\section{MATERIAL AND METHOD}

The study comprised of 50 patients selected from the routine ENT OPD with septal deviation and inferior nasal concha hypertrophy in contralateral nasal cavity.

Inferior nasal concha on the contralateral side of deviation were included in the study group and those on the side of deviation as the control group. Before decongestion with $0.05 \%$ oxymetazoline computed tomography scans of the paranasal sinuses were performed continuously from anterior to posterior with $5 \mathrm{~mm}$ slices in coronal plane. The anteriorposterior length of the hypertrophy and the control nasal concha were calculated by multiplying the slice number by the slice thickness. By dividing the total length by three, the length of the anterior, middle and posterior portions of the nasal conchas were determined. The thickest site in each portion of the nasal concha were selected for measurement. Measurement of the thickness of the medial mucosa, bones, lateral mucosa were taken separately on the anterior, middle $\&$ posterior portions of inferior nasal conchas at a place perpendicular to the mucosal surface in both the hypertrophied inferior nasal concha and the control group with the aid of a cursor on the screen of computed tomography (Figs. 1 and 2).

Measurements were compared by paired Sample (t) test and expressed as mean values $+2 \mathrm{SD}$. A probability value (P Value) $<0.05$ were significant.

\section{RESULTS}

Table I shows mean value of the anterior, middle and the posterior part of the inferior nasal concha in the control and the hypertrophic group.

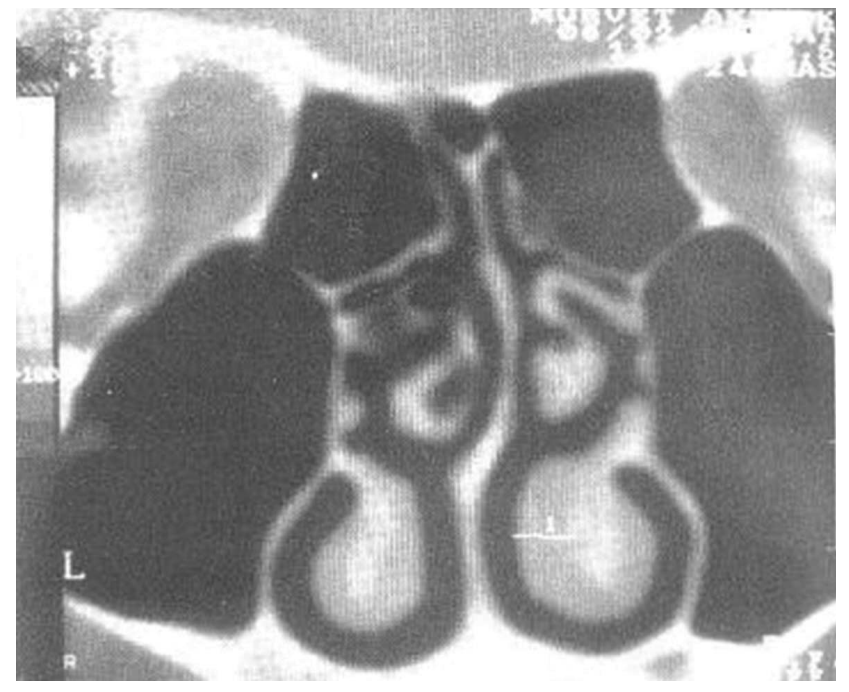

Fig.1. Measurement of the thickness of medial mucosa of the inferior nasal concha.

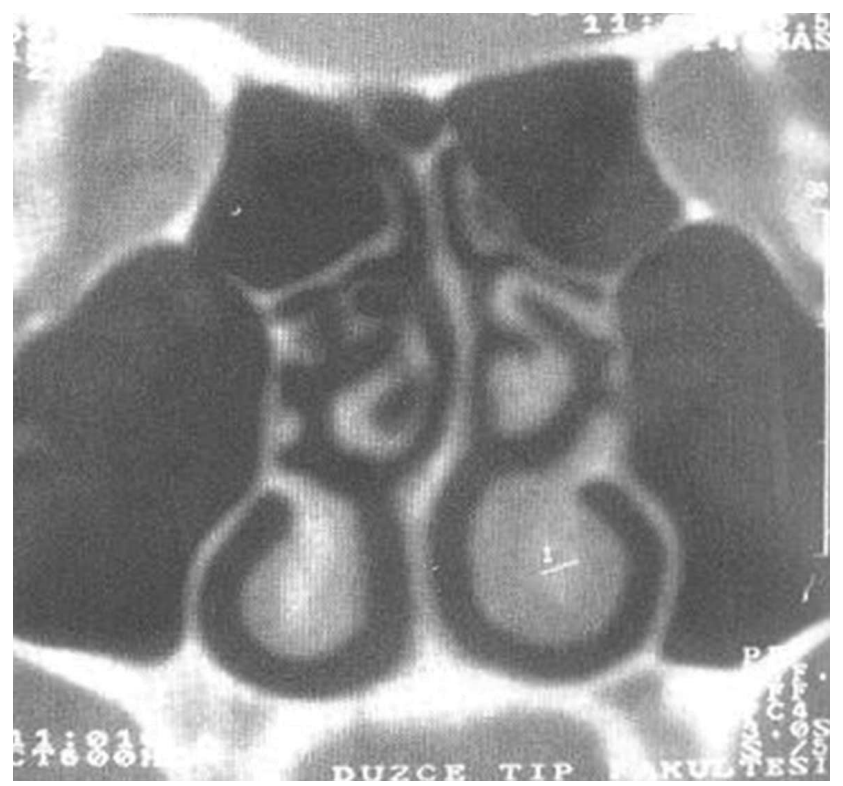

Fig. 2. Shows measurement of the thickness of bone of the inferior nasal concha.

Table I. Median mucosa undergoes maximum hypertrophy as compared to bone and lateral mucosa. The anterior part and the middle part of the bone which hypertrophies more than the posterior part.

\begin{tabular}{lcccccccccccc}
\hline & \multicolumn{3}{c}{ Total width $(\mathbf{m m})$} & \multicolumn{3}{c}{ Medial mucosa $(\mathbf{m m})$} & \multicolumn{3}{c}{ Bone(mm) } & \multicolumn{3}{c}{ Lateral mucosa (mm) } \\
\cline { 2 - 12 } & AD & MD & PD & AD & MD & PD & AD & MD & PD & AD & MD & PD \\
\hline Ant Cgp & 5.56 & 5.58 & 5.54 & 3.36 & 3.36 & 3.40 & 1.0 & 0.99 & 0.96 & 1.27 & 1.29 & 1.24 \\
Ant Htgp & 9.95 & 10.01 & 10.2 & 5.12 & 5.17 & 5.33 & 1.8 & 1.78 & 1.70 & 1.27 & 3.03 & 3.23 \\
\hline
\end{tabular}


MRIG, S.; AGARWAL; A. K. \& PASSEY, J. C. Preoperative computed tomographic evaluation of inferior turbinate hypertrophy and its role in deciding surgical treatment modality in patients with deviated nasal septum. Int. J. Morphol., 27(2):503-506, 2009.

\section{DISCUSSION}

Histologically, the inferior nasal concha is composed of three layers: medial and lateral mucosal layers and a central osseous layer between them. The medial layer is considerably thicker than the lateral layer. Surgically it is important to note that the nasal concha bone is thicker anteriorly than posteriorly. The internal nasal valve accounts for $50 \%$ of total airway resistance. It is in this region that the inferior nasal concha can exert its maximum role on nasal airway resistance. Anatomic causes of nasal obstruction include problems with the inferior nasal concha, the septum, and the nasal valve. Septal deviation can lead to obstruction of one nasal airway with compensatory hypertrophy of the contra lateral inferior nasal concha. The reason of this hypertrophy is not entirely clear, but it can lead to nasal obstruction when the nasal cycle causes engorgement of the enlarged nasal concha. A histologic study by Berger et al. showed that the most commonly enlarged component of the contralateral inferior nasal concha in septal deviation is the bony nasal concha. This suggests that themucosal swelling is not solely responsible for nasal obstruction in these patients. Inferior nasal concha hypertrophy is a frequent cause of nasal airway obstruction. Epidemiological investigations have shown that up to $20 \%$ of the population had chronic nasal obstruction caused by nasal concha hypertrophy. Symptoms of nasal obstruction may persist despite maximal medical management. So surgical procedures that reduce the size of the inferior nasal concha can not only improve symptoms, but can also potentiate medical management of rhinitis. Procedures can be classified as those that address bony causes of nasal obstruction, and those that address mucous and submucous swelling. Studies report that septal surgery without nasal concha reduction results in relief of nasal obstruction in $71 \%-80 \%$ of patients. It has been seen in the past studies that patients undergoing septoplasty without turbinoplasty had no benefits from the surgery because of relocation of septum towards the mid line and further reduction in the nasal airway patency on the opposite side. It had always been a subject of debate whether to add turbinopalsty to standard procedure of septoplasty and if to perform turbinoplasty then what surgery to perform i.e., whether to reduce the mucosal component or reduce the bony component.

In our study on basis of NCCT paranasal sinuses it was seen that is the middle part of inferior nasal concha that undergoes maximum hypertrophy followed by anterior part and the posterior part undergoes least hypertrophy. The average mean value of the middle part of the inferior nasal concha was $5.58 \mathrm{~mm}$ for the control nasal concha and 10.01 $\mathrm{mm}$ for the hypertrophic nasal concha as compared to 5.56 and $5.54 \mathrm{~mm}$ in the anterior and posterior part of the inferior nasal concha in the control group and 9.95 and $10.2 \mathrm{~mm}$ for the anterior and posterior part of the inferior nasal concha in the hypertropic group. Also out of all the three component of the inferior nasal concha it is the medial mucous which undergoes maximum hypertrophy as compared to bone and lateral mucosa. The average thickness of medial mucosa was $5.12 \mathrm{~mm}, 5.17 \mathrm{~mm}$ and $5.33 \mathrm{~mm}$ in the anterior, middle and the posterior portion of the inferior nasal concha as compared the thickness of lateral mucosa and bone which was 1.27 $\mathrm{mm}, 3.03 \mathrm{~mm}$ and 3.24 and $1.8 \mathrm{~mm}, 1.78 \mathrm{~mm}$ and $1.70 \mathrm{~mm}$ in the anterior, middle and the posterior portion of the inferior nasal concha. It was also seen that on the basis of statistics calculated the 'p' value was significant i.e., it was $<0.05$ in the hypertrophic group which means that there is definitely a difference in the thickness of the control nasal concha and the hypertorphic nasal concha and shows that the contralateral nasal concha undergoes hypetrophy opposite to anterior septal deviation. It was also seen that the bone undergoes more hypertrophy anteriorly than posteriorly. The bone thickness in the hypertropic group was maximum in the anterior part of the inferior nasal concha i.e., $1.8 \mathrm{~mm}$ as compared to 1.78 and 1.7 in the middle and the posterior part of the inferior nasal concha.

\section{CONCLUSIONS}

The following conclusion can be made from the study.

1. The medial mucosa undergoes maximum hypertrophy as compared to the bone and the lateral mucosa.

2. Computed tomography is a non invasive technique in assessing the anatomical composition of inferior nasal concha and helps in deciding the type of turbinoplasty depending upon the type of hypertrophy.

3. Addition of turbinoplasty to septoplasty is advisable in terms of relief of nasal obstruction which is not achieved or rather decreased after conventional septoplasty due to rellocation of the septum to the midline.

4. It is not only the mucosal component which gests hypertrophied but also the bone which also undergoes hypertrophy and adds to increased nasal resistance in the anterior part of the nose. 
MRIG, S.; AGARWAL; A. K. \& PASSEY, J. C. Evaluación preoperatoria con tomografía computada de la hipertrofia de la concha inferior y su rol en la decisión de la modalidad de tratamiento quirúrgico en pacientes con tabique nasal desviado. Int. J. Morphol., 27(2):503-506, 2009.

RESUMEN: Un tabique nasal desviado está asociado con una hipertrofia compensatoria de la concha nasal inferior del lado contra lateral. En el pasado se realizaba septoplastía convencional para el tabique desviado, lo que mejoraraba la permeabilidad en el lado de la desviación, pero agravaba ésta en el lado opuesto, debido a la reacomodación del tabique en el plano mediano. En el presente estudio se evaluó en 50 pacientes la composición anatómica de las conchas nasales inferiores, basado en la exploración a través de tomografía computarizada, y de esta manera ayudar al otorrinolaringólogo a determinar si es necesario o no, añadir la plastía de la concha nasal inferior al procedimiento de septoplastía estándar.

PALABRAS CLAVE: Tabique nasal desviado; Concha nasal inferior; Hipertrofia contralateral.

\section{REFERENCES}

Berger, G.; Hammel, I.; Berger, R.; Avraham, S. \& Ophir, D. Histopathology of the inferior nasal concha with compensatory hypertrophy in patients with deviated nasal septum. Laryngoscope, 111(12):2100--5, 2000.

Casserius, J. Pentaesthesion. Venice, Italy, N. Misserinuon, 1609. pp.112-5

Dixon, F. W. The nasal turbinates. Trans. Am. Acad. Ophthalmol. Otolaryngol., 54:107-12, 1949.

Fairbanks, D. N. Snoring: surgical vs. nonsurgical management. Laryngoscope, 94(9):1188-92, 1984.

Haight, J. S. \& Cole, P. The site and function of the nasal valve. Laryngoscope, 93(1):49-55, 1983.

Lai, V. W. \& Corey, J. P. The objective assessment of nasal patency. Ear Nose Throat J., 72(6):395-400, 1993.

Li, K. K.; Powell, N. B.; Riley, R. W.; Troell, R. J. \& Guilleminault, C. Radiofrequency volumetric tissue reduction for treatment of turbinate hypertrophy: a pilot study. Otolaryngol. Head Neck Surg., 119(6):569-73, 1998.

Pratt, J. A. Conservation of turbinates. Trans. Am. Acad. Ophthalmol. Otolaryngol., 20:136, 1915.

Proetz, A. W. Physiology of the nose from the standpoint of the plastic surgeon. Arch. Otolaryngol., 39(6):514-7, 1944.

Seeger, J.; Zenev, E.; Gundlach, P.; Stein, T. \& Müller, G. Bipolar radiofrequency- induced thermotherapy of turbinate hypertrophy. Pilot study and 20 months' follow up. Laryngoscope, 113(1):130-5, 2003.
Correspondence to:

Dr. Sumit Mrig

C- 30 (Ff) Lajpat Nagar - 1

New Delhi - 110024

INDIA

Telephone: +91- 9868242525

Email: drsumitmrig@gmail.com

Received: 13-10-2008

Accepted: 24-02-2009 